\title{
Physical Fitness on Academic Performance in Youth
}

\section{Najada Quka}

$\mathrm{PhD}$

Rigerta Selenica

$\mathrm{PhD}$, Sports University of Tirane, Faculty of Movement

Sciences, Department of Education and Health

\section{Abstract}

Physical fitness, as an important physical health issue, may play a key role also in brain health by affecting the academic performance of youth helping the cognitive control components to improve. Memory and cognitive skill are some of the cognitive control components that are fundamental even for academic ability. Aim: In this context, the aim of our study was to investigate and analyze the facts regarding the potential of the exercises on academic achievement improvement. Methods: In order to realize a detailed review study we used the Jab Ref as a research sector, focusing more on navigating the Medline, Google Scholar, and Inspire options that this program contains. While as the selection criteria of the collected scientific articles, we used the keywords that provided us the exact articles that stated facts about the aim of our study. Results: Authors emphasized that the development of motor skills by practicing the coordinative exercises may have a beneficial influence on the learning process improving academic performance. This comes out because of the coordinative exercise's impact on increasing the number of neuron transmitters and the new neural connections that enable youth to have a better perception regarding motor and academic situations. In addition, the authors underline the fact that the most active youth tend to perform better academically.

Keywords: physical fitness, cognitive aspects, academic ability, academic performance, youth.

\section{Introduction}

Physical fitness, as an important physical health issue, may play a key role in brain health and academic performance. Being active in life is very important because of its multidimensional effects due to many health aspects in different age groups, especially among young people providing a healthy adult. Many physical activity benefits are clearly shown; however, some of them are still unclear. For decades, 
physical activity has been one of the most interesting scientific issues because of its derived benefits. Recently, the focus of many studies has been due to academic performance and its improvement via regular physical activity. Some of the data stated its positive impact on academic performance emphasizing that muscles are not the only part of the body that changes physically and chemically because of physical activity even the brain can change too. These changes are related to the improvement of the ability to be the focus or to stay alert during the learning process, influencing also the memory systems. These cognitive control components such as memory and cognitive skill are determined as the fundamental aspects of academic ability. (IreneCornejo et al, 2014) Despite the positive changes that physical activity may cause on academic performance, few studies show no significant impact. According to the U.S. Department of Health and Human Services, in Atlanta, 2010, children and adolescents who exercised for at least 60 minutes a day can easily get multiple health benefits. In addition to this recommendation and the multiple benefits of physical activity in children's health, many schools increased the time devoted to physical activities during school time (CDC, 2010).

This occurred even in Albanian Educational Policies, increasing the physical education classes from 2 to 3 hours per week since 2015, but there is no data regarding its impact on the learning process among Albanian children. The effects of regular physical activity on several health issues such as physical, motor, social, and emotional in youth are clearly shown by many studies, while the impact of it on academic performance continues to be unclear because of diverse data.

The impact of physical activity on improving academic performance sparked our curiosity to study more deeply about this issue. What we really want to achieve with this study is the promotion of this significant impact of physical fitness on improving academic performance. Based on how physical fitness might improve academic performance, a piece of detailed and clear information is important to build up for all of those who are or are not engaged in regular physical activity or physical education class, by motivating them due to it for a better and easier learning process.

Lopes and his colleges, in 2013 after their long review-work focused on many foreign scientific studies, revealed that the brain loves exercising. The brain undergoes several physiological changes because of physical activity, which might be responsible for many important learning process mechanisms as even Trudeau (Lopes et al., 2013; Trudeau F., et al, 2008) underlined it. Some of these brain's physiological and chemical changes that might influence positively some of learning process components are shown in table 1 :

\section{Table 1:}

ImpactofPhysical Activity on Learning Process

(Based on CDC declare in 2010)

\begin{tabular}{l|l} 
Brain's Physiological changes & Learning Process
\end{tabular} 


\begin{tabular}{|l|l|}
\hline Blood flow and more oxygen & Attention \\
\hline $\begin{array}{l}\text { Dopamine release } \\
\text { Norepinephrine release, responsible for focus and } \\
\text { attention. }\end{array}$ & Motivation \\
\hline $\begin{array}{l}\text { Growth of nerve cells in the Hippocampus, learning } \\
\text { center of the brain }\end{array}$ & Memory \\
\hline $\begin{array}{l}\text { Serotonin release, responsible for memory, } \\
\text { learning, regulating sleep and mood patterns }\end{array}$ & Problem-solving \\
\hline Brain cells grow & Mental clarity \\
\hline Development of nerve connections. & Improved information processing \\
\hline The density of the neural network & Learning ability \\
\hline Brain tissue volume & Focus \\
\hline
\end{tabular}

Lopes and his colleges emphasized that physical activity as an important issue that improves coordination skills can indirectly influence a better learning process as long as these skills are directly dependent on neural function and visual perception (Lopes L., et al 2013). This is one of the many reasons why the development of coordination skills is recommended for preschool-aged children. Increasing the number of neuron transmitters and new neural connections by engaging in physical activity as is recommended, enables children to better and easily percept the different motor or academic situations during the learning process. Perception is a process with some actions such as selection of impulses, organization, planning, and implementation of the created perception. The entire actions that take place in the brain are very important for the learning process.

The importance of coordinative skills development is shown even by Marga Grey in 2000, as a pediatric therapist and childhood development expert. According to her, coordinative skills are very important to be developed not only for a better future life but alsofor their importance on academic performance improvements. In addition, she emphasized that the development of fine motor skills since preschool-age children is a strong acquisition for later reading and maths achieved scores. Furthermore, fluid intelligence such as logical thinking and problem-solving can be improved by bilateral coordination exercises (Marga Grey, 2000).

These positive impacts of the coordinative skills development on some learning mechanisms are emphasized even in 2018 from Macdonald and her colleague underling the importance of early fine and gross motor development have funny and easy learning process improving also their academic achievements. These positive influences are related to the increased neural connections because of coordinative exercises that are responsible even during the learning process helping the brain to get accurate problem-solving (Macdonald et al., 2018).

Other positive influences are detected in the learning process at those who participate regularly in physical activities organized during or after school. Children can be better concentrated on classroom tasks almost immediately after engaging in physical 
activities increasing also their standardized test score (6\% over three years). These outcomes are results of coordinative education classes not from traditional physical education classes focused on team sports. Furthermore, better scores on academic tests by improving concentration may result even by single sessions of physical activity among children. In addition, it might reduce $21 \%$ of teachers' time managing children's academic behaviors that are also positively affected by being active.

These brain reactions come out because of some changes like increased blood circulation, oxygen volume, and nutrients improving mental activity (Robert Wood Johnson Foundation, 2015; figure 1).

\section{Fig.1 Brain Scan Test \\ ACTIVE KIDS LEARN BETTER}

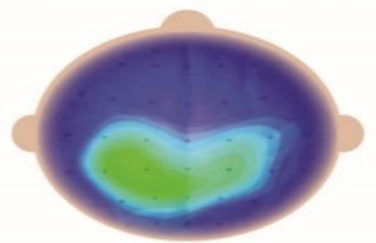

After 20 minutes of sitting position

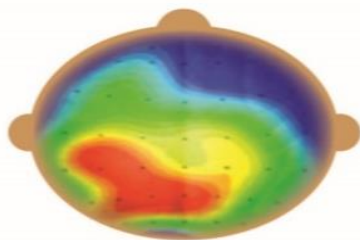

After 20 minutes of walking

** Red areas show when children are active, the blue area shows when children are less active (Robert Wood Johnson Foundation, 2015)

Improving perception skills is very important but before it, all teachers might ensure children's concentration and attention. If they are very concentrated on paying attention to the academic tasks, they will select the adequate visual, auditory, or tactile stimuli necessary for better academic performance.

Furthermore, $C D C$ in 2010 revealed that regular physical activity could provide some positive influences on cognitive skills such as attention; memory, verbal comprehension, information processing, and motivation (CDC, 2010).

The cognitive improvements, which reflect on the classroom test scores are supported even by McPhersonin 2018 who detected the impact of physical activity on learning through cognition skills examined on 601 New Zealand children aged 6-11 years old (McPherson et al., 2018).

According to Ericsson and his colleagues, the development of motor skills among 7-9 years old influenced positively attention and impulse control ability affecting academic performance especially on reading-writing and spatial ability in math and number perception (Ericsson, 2008). This result showed us how important is to promote and apply physical activity like an old saying that "Learning through playing games is more effective and funny".

The impact of physical activity on concentration ability during the learning process is detected since 1990 studied on children aged 11-12 years old. According to Raviv and 
Low's results, the concentration ability is higher when physical activity is applied at the begging of the day and at the end of the lesson (Raviv\& Low, 1990). The ability to concentrate on every task helps children to produce adequate cognitive and motor perception performing accurately the required task. Like many other researchers, even Rasberrya and his colleagues in 2011 noticed the positive impact of physical activity on academic performance and exactly on cognitive abilities, academic behavior, and academic achievement supported by $50 \%$ of their reviewed articles (Rasberrya et al., 2011).

Another indicator of academic performance that can be influenced positively by regular physical activity is classroom behaviors, except the cognitive skills that the dominance of studies has approved. This helps children and teachers to pay more attention to the achievement of the academic task facilitating the learning and teaching process (Fernandes et al., 2016).

No one can remain indifferent to such findings, especially those who are part of the new generation education promoting physical activity among all school-age children and focussing on those exercises that this review showed influence on various indicators of academic performance.

\section{Research Methods}

Our review aimed to analyze as much data as possible in order to summarize the existed information regarding the learning process and the possible impact of physical activity on it. To gather as much data as possible data we used the electronic scientific sectors with high scientific research reliability in order to get all the comprehensive findings for this study. To be more specific, we investigated more on Research Gate, Jab Ref, Pub Med, Medline, and GoogleScholar electronic sectors. From 50 research articles detected from investigative sectors, we analyzed only 12 research articles. This focus is based on the selection criteria focusing more on the coherence of the data. We included both the experimental and observational scientific studies, without excluding the oldest one. These criteria helped us to build up a timely comparison of data about this important topic informing every school-age group, the pedagogical professional, and school policy for the children's immediate acquisition for better academic performance.

\section{Discussion}

Based on the facts that our reviwed articles, we detected that the physical fitness promotion in youth play an important role not only due to an healthy future of their social, physical and emotional development, also due to a better aand easier learning process improving their academic scores. The intellectual aspect is shown to be an addited benefit of the physical fitness affected by the systematic physical exercises participation of the youth.

In addition, most of the studies have shown the positive effect of physical activity on academic performance improving some learning indicators such as attention, 
decision-making, academic attitudes, and cognitive aspects. (Rasberrya et al., 2011) The variety of findings is the result of different methodological quality levels used, because of different Physical Activity programs implemented and the different indicators of academic performance that they examined. However, this diversity showed us the necessity to be more specific in the future about this issue.

There are studies emphasizing that the brain loves the exercise and it undergoes it due to several physiological and chemical changes that are very important for the learning process affecting them positively. (Lopes et al., 2013; Trudeau F., et al, 2008)

Being active by participating for at least 60 minutes a day in different physical activities is a demand recommendation to easily get multiple health benefits. The most recommended exercises are the coordinative one because of its influence on increasing the neuron's transmitter number and new neural connections helping children to easily percept the different motor or academic situations during the learning process. It is also emphasized that the traditional physical activity class by using team sports cannot have the same impact on academic components like coordinative skills focusing on fine and gross motor skills development (Marga Grey, 2000; Macdonald et al., 2018).

At the end of our discussion we detected that the physical fitness is essential is associated with academic performance via its impact on cognitive skill improvements such as attention; memory, concentration, perception, decision making, problemsolving. These cognitive improvements reflect on reading-writing, spatial ability in math, and number perception improving the academic performance.

\section{Conclusion and Recommendation}

Classroom behavior and cognitive skills are important indicators of learning process accuracy, and they can be positively influenced by physical activity helping children and teachers to pay more attention to the academic task achievements.

After a detailed analysis of the reviewed data, they were focused more on the impact of physical activity on three learning components such as cognitive skills, academic behavior, and academic achievement. All of this showed us a variety of changes that happen in children's brain functions and their behaviors because of P.A helping them academically. These positive impacts of physical activity on academic performance are significantly shown by many studies, despite that few of them show no significant relationship between these two variables. These diverse results enhance our responsibility as specialists in movement science to realize further studies in order to clarify these significant and positive influences of an active life due to better academic performance.

At the end of our review, we can emphasize that still this issue needs further experimental studies in order to clarify the few doubts and no significances evidenced so far. 
Despite these scientific necessities for further studies, it is known that physical activity has a positive influence on the academic performance of children affecting different mechanisms of the learning process.

Findings that so far emphasized the positive influence of exercises on the learning process may inform and help school policies and pedagogical approaches to focus their priorities more on the importance of motor skills development due to better learning process since the early years of school. Furthermore, this topic is relevant to both education and teaching professionals (since preschooler and following) through the promotion of regular participation in physical activities by developing motor skills, as this may also influence due to better academic performance, should consider prioritizing all of this immediate children's acquisition.

We recommend that future studies need to focus more on the significance of physical fitness on the learning process starting from early school age and so on. Also, we recommend that the focus of physical education teachers must be on the coordinative exercises influencing the development of youth coordination skills and their cognitive abilities.

\section{References}

[1] Centers for Disease Control and Prevention. (2010). The association between schools based physical activity, including physical education, and academic performance. Atlanta, GA: U.S. Department of Health and Human Services.

[2] Ericsson I. (2008). Motor skills, attention, and academic achievements: an intervention study in school years 1-3. British Educational Research Journal; 34(3):301-313.

[3] Irene-Cornejo E., Tejero-Gonzalez C.M., Martinez-Gomez D., ,Del-Campo J., Gonzalez-Galo A., Padilla-Moledo C., Sallis J.F and Veiga O.L. UP \& DOWN Study Group. (2014). Independent and Combined Influence of the Components of Physical Fitness on Academic Performance in Youth. The Journal of Pediatrics, original article. Vol.165; No.2; pg. 306-312 www.jpeds.com

[4] Fernandes, V.R., Scipião Ribeiro, M.L., Telo, Th., TarsoMaciel-Pinheiro, P., Guimarães, Th.T., Araújo, N.B., Ribeiro, S., \& Deslandes, A.C. (2016). Motor Coordination Correlates with Academic Achievement and Cognitive Function in Children Frontiers in Psychology, Volume 7 | Article 318.

[5] Lopes, L., Santos, R., Pereira, B., \& Lopes, V.P. (2013). Associations between gross Motor Coordination and Academic Achievement in elementary school children. Human Movement Science, 32, pg.: 9-20.

[6] McPherson, A., Mackay, L., Kunkel, J., \& Duncan, S. (2018). Physical activity, cognition and academic performance: an analysis of mediating and confounding relationships in primary school children. BMC Public Health 18:936https://doi.org/10.1186/s12889-018-5863-1 
[7] Macdonald, K., Milne, N., Orr, R., \& Pope, R. (2018). Relationships between Motor Proficiency and Academic Performance in Mathematics and Reading in School-Aged Children and Adolescents: A Systematic Review. Int. J. Environ. Res. Public Health, 15, 1603.

[8] Marga Gray. A pediatric therapist. (2000). The link between movement and academic performance. Online Available:

https://www.sourcekids.com.au/the-link-between-movement-andacademic-performance/

[9] Raviv, S., \& Low, M.(1990). Influence of physical activity on concentration among junior-high-school students. Perceptual and Motor Skills Journal; 70(1):67-74.

[10] Rasberrya, C.N., Leea, S.M., Robina, L., Larisb, B.A., Russellb, L. A.,.Coyleb, K.K.,\&Nihisera, A.J. (2011). The association between school-based physical activity, including physical education, and academic performance: $\mathrm{A}$ systematic review of the literature. Preventive Medicine.Volume 52, Pages S10-S20

[11] Robert Wood Johnson Foundation production. (2015). Active Living Research. Promoting activity-friendly communities. Research Brief: Active Education: Growing Evidence on Physical Activity and Academic Performance.

[12] Trudeau, F., \& Shephard, R.J. (2008). Physical education, school physical activity, school sports, and academic performance. International Journal of Behavioural Nutrition and Physical Activity; 5(10). 